\title{
En torno a los depósitos de la Edad del Bronce
}

\author{
Amparo Hernando Grande *
}

Agrupamos bajo esta denominación, aquellos yacimientos que las fuentes bibliográficas nos presentan como un conjunto de piezas intencionadamente depositadas juntas, son los «depósitos cerrados». Estos depósitos, aparte de su intencionalidad, tienen otros dos factores comunes, como son, el estar formados única y exclusivamente por materiales metálicos, siendo las armas las que alcanzan en ellos el mayor grado de representatividad, y en segundo lugar, el hecho de que nunca se constatan asociados a otros materiales, que no sean, obviamente, los que respectivamente les conforman, ni relacionados a un tipo de yacimiento concreto.

En un reciente trabajo de investigación que realizamos acerca del armamento metálico en la meseta peninsular, pudimos comprobar como un considerable número de armas del tipo que estudiábamos procedian de depósitos, hecho éste que nos llamó poderosamente la atención, hasta tal punto, que nos distrajo del objetivo final de nuestro estudio, que era el análisis de las armas y su posible encuadre cultural, pero con la idea de reflexionar, en un futuro, sobre la forma en que se manifiesta el armamento del Bronce Final.

Entre estos depósitos, que consideramos se dan las características que definen al depósito "puro", se encuentran el de Padilla de Abajo y Huerta de Arriba en la provincia de Burgos, Barrio Placa de Ponferrada y Represa en la de León, Saldaña y Castromocho en la provincia de $\mathrm{Pa}$ lencia, Covaleda, Ocenilla y Layna en la de Soria (fig. 1).

\footnotetext{
* Departamento de Prehistoria e Historia Antigua, UNED.
} 


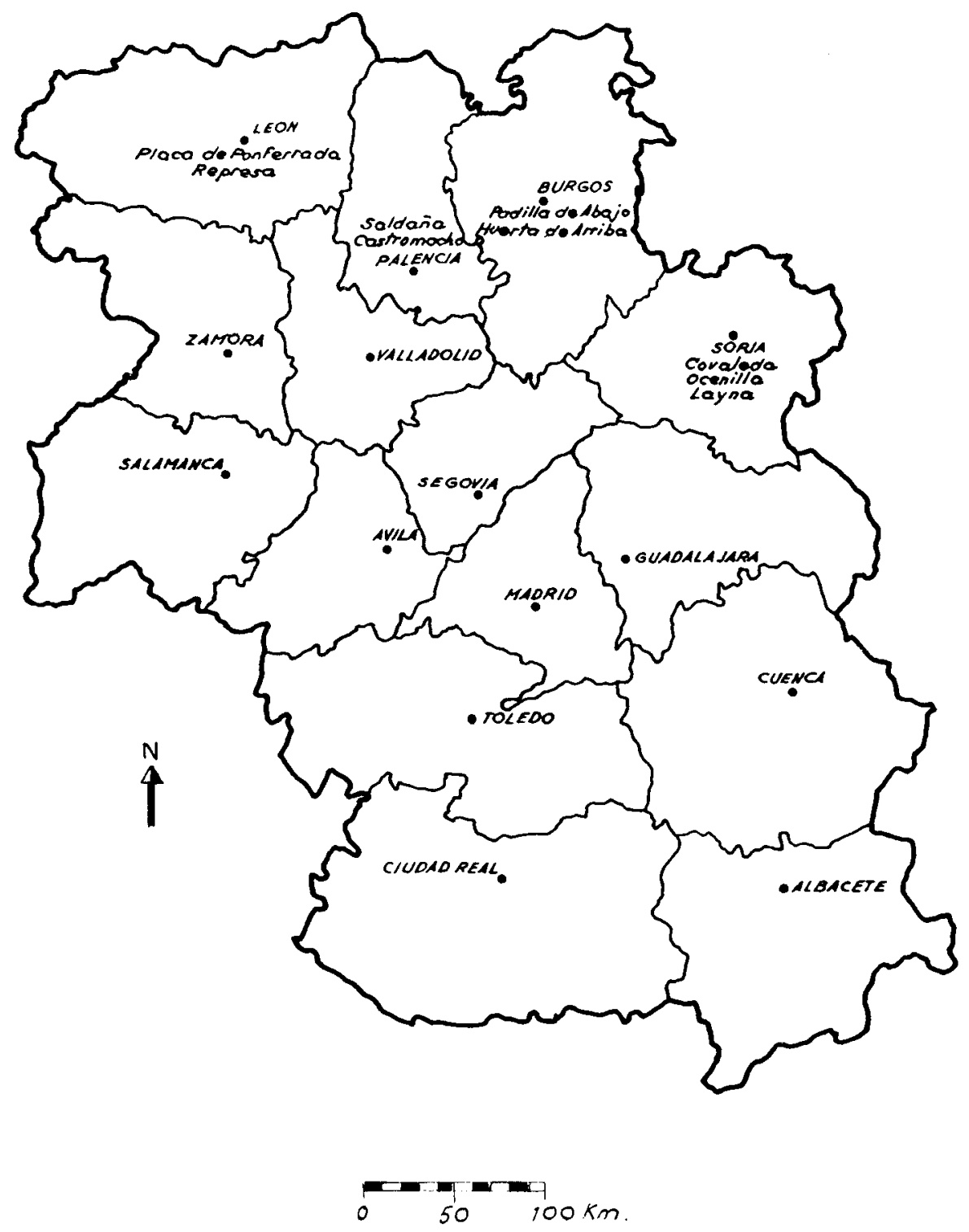

Fig. 1. Dispersión de los depósitos tratados. 
Padilla de Abajo. - Este depósito consta de: un hacha plana con anillas laterales (fig. 2); una punta de flecha palmela (fig. 3); una punta de lanza tubular (fig. 4), y cinco brazaletes acintados. Todos estos materiales están fabricados en bronce.

Huerta de Arriba.- Este depósito consta de: tres hachas con nervio central, con anillas laterales y con talón o tope (figs. 5, 6 y 7); dos puñales con remaches y lengüeta y nervio central (figs. 8 y 9 ); un puñal de lengüeta (fig. 10); una punta de lanza tubular con prolongación en nervio (fig. 11); cuatro navajas de afeitar; dos brazaletes, y una lezna de doble punta. Todos los materiales fabricados en bronce.

Barrio placa de Ponferrada.-Este depósito consta de: un hacha con nervio central, anillas laterales y talón o tope (fig. 12). Observación: el depósito estaba formado por ocho hachas de tipología semejante, sólo de la citada tenemos información. Realizadas en bronce.

Represa.-El depósito consta de: tres lanzas tubulares con prolongación en nervio (figs. 13, 14 y 15).

Saldaña.-Este depósito consta de: un hacha plana trapezoidal (fig. 16); un hacha plana campanulada (fig. 17); un hacha plana con apéndices laterales (fig. 18); dos hachas con nervio central, anillas laterales y talón (figs. 19 y 20); puñal con nervio y empuñadura indeterminada (fig. 21); puñal con nervio central y punta "gota de sebo", con empuñadura indeterminada (fig. 22), y un regatón de lanza. Todos los materiales fabricados en bronce.

Castromocho.-Este depósito consta de: tres puntas de lanza tubulares con prolongación en nervio (figs. 23,24 y 25). Todas fabricadas en bronce.

Covaleda.-Este depósito consta de: dos hachas con nervio central, anillas laterales y talón (figs. 26 y 27); un hacha plana con anillas laterales y talón (fig. 28); un hacha plana con apéndices laterales (fig. 29), y un regatón de lanza. Fabricados en bronce. 

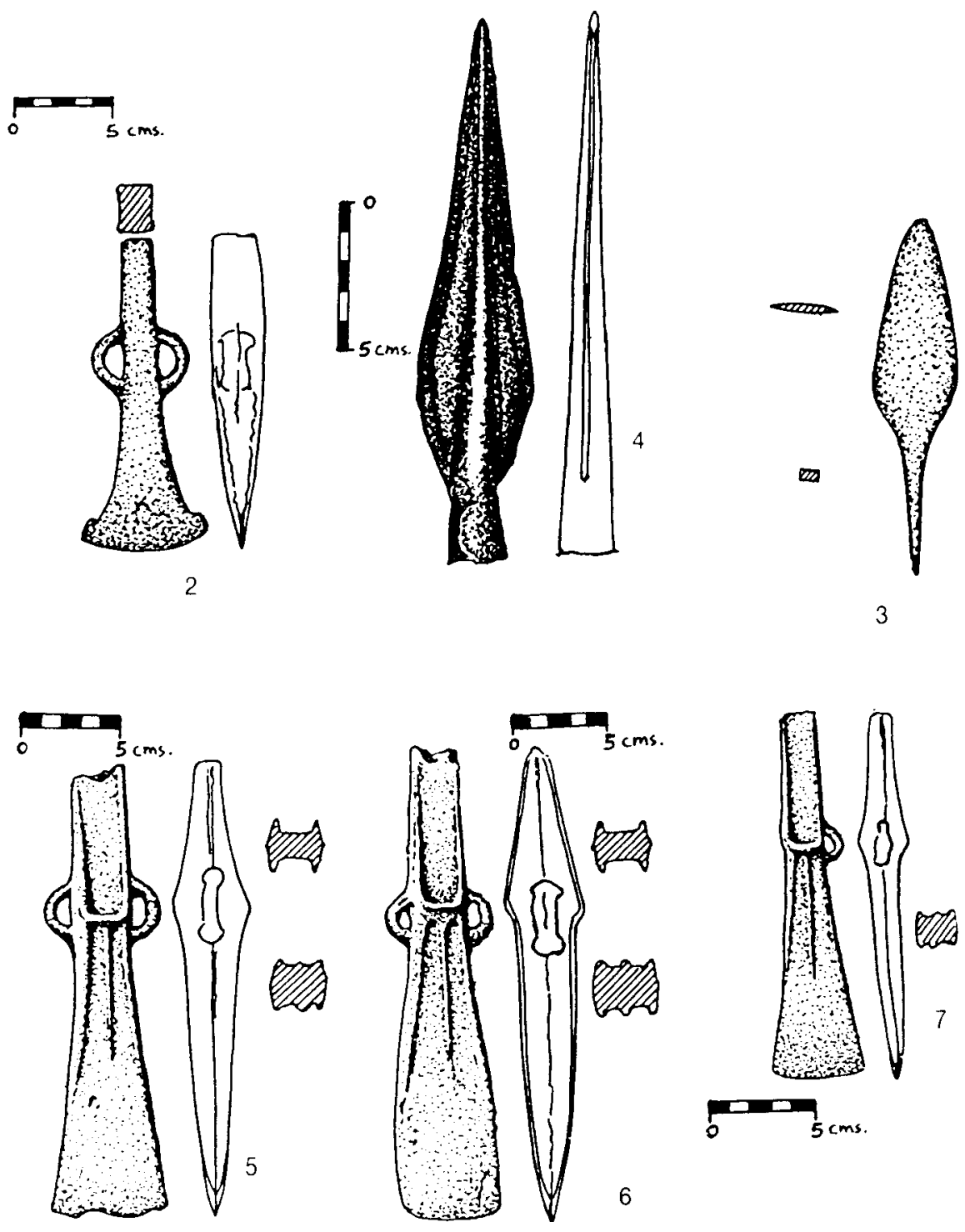

Padilla de Abajo, figs. 2, 3 y 4; Huerta de Arriba, figs. 5, 6 y 7 . 


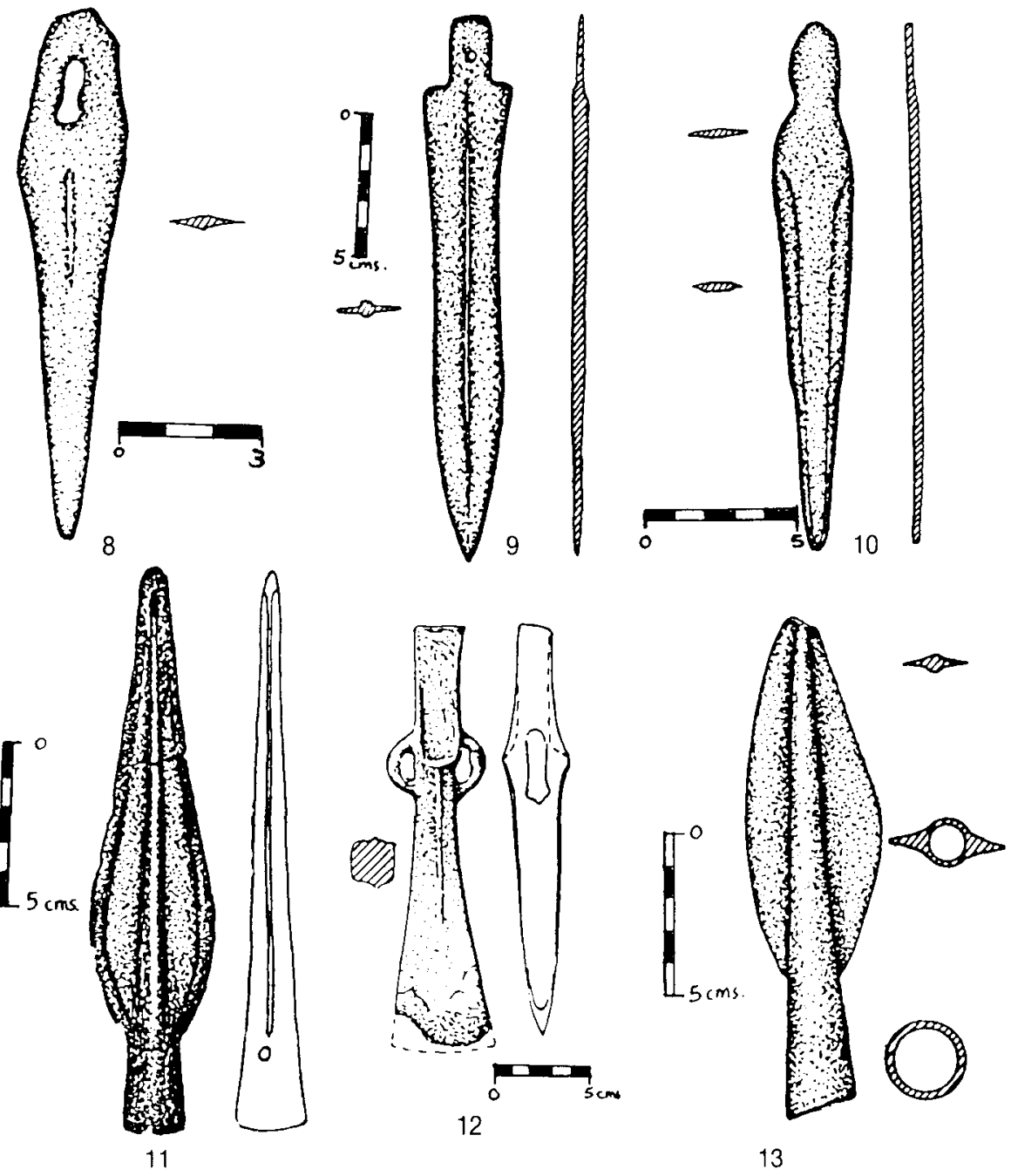

Huerta de Arriba, figs. 8, 9, 10 y 11; Placa de Ponferrada, fig. 12; Represa, fig. 13. 


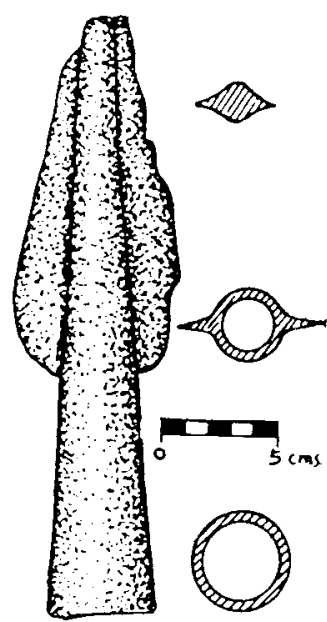

14

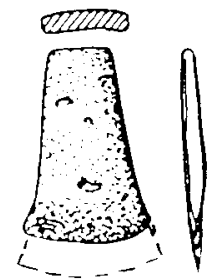

scms.

17

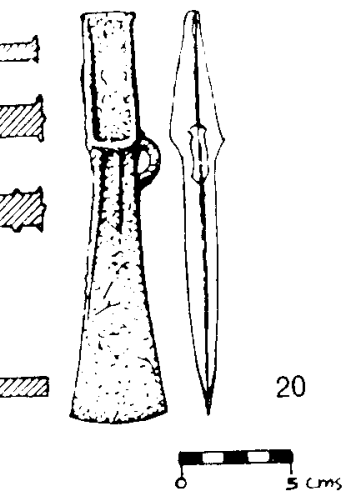

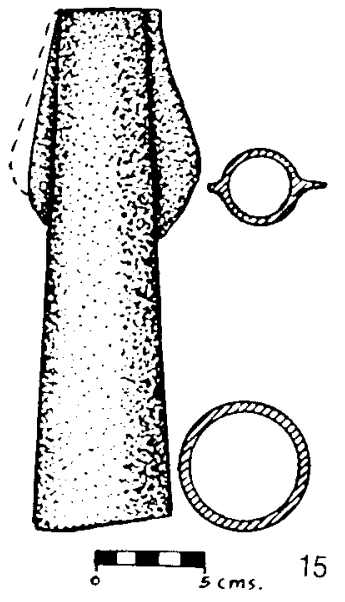

QUZWD

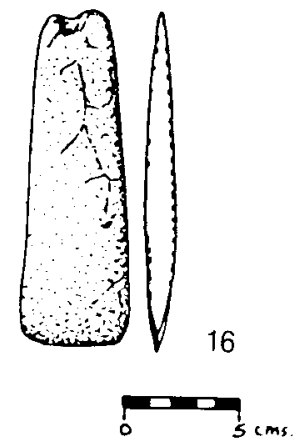

15
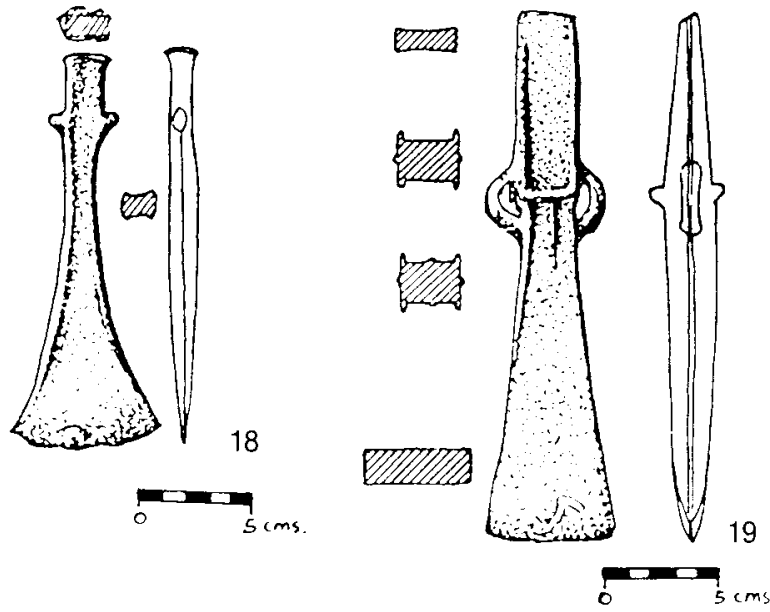

Represa, figs. 14 y 15; Saldaña, figs. 16, 17, 18, 19 y 20. 
En torno a los depósitos de la Edad del Bronce
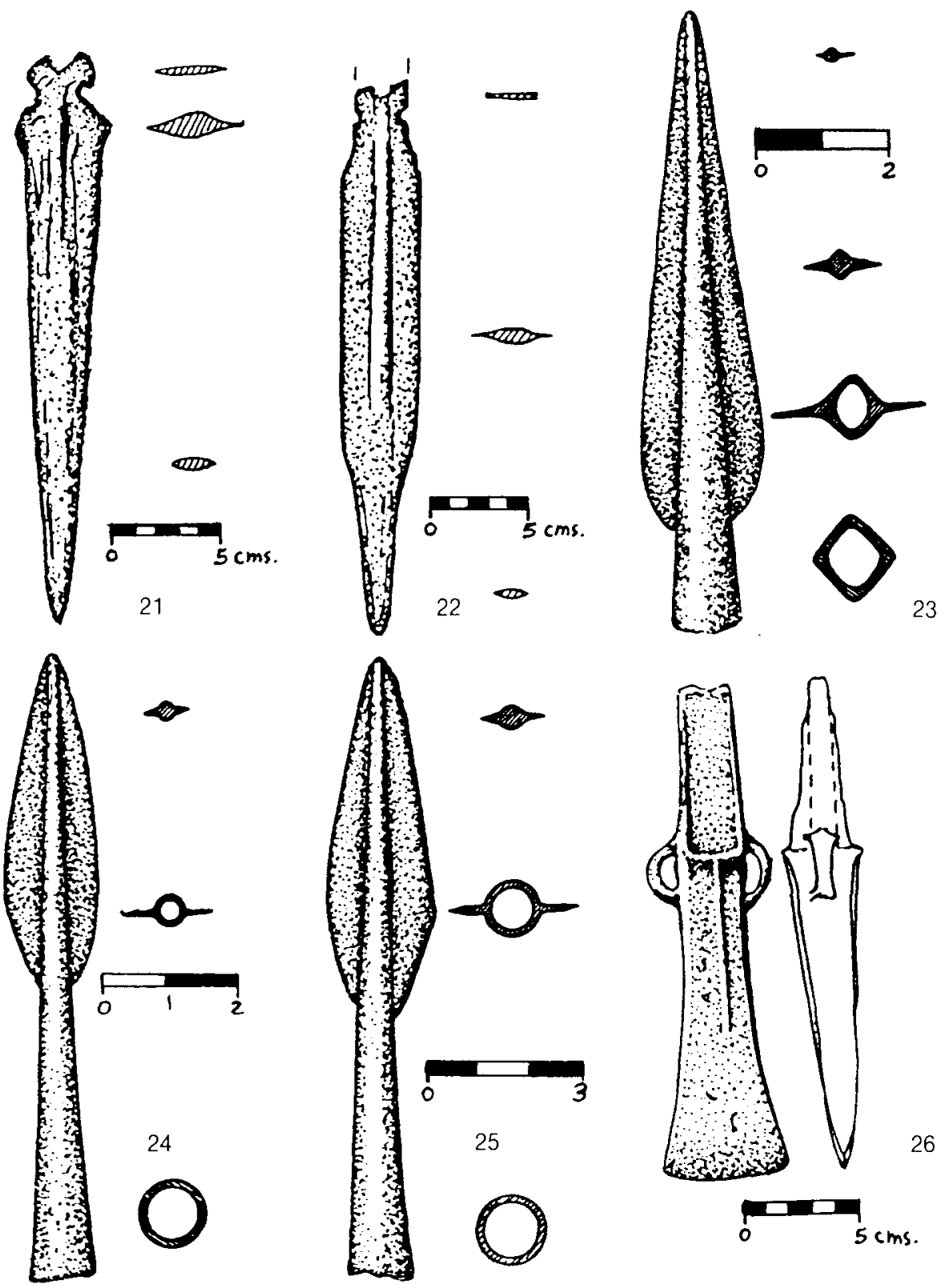

Saldaña. figs. 21 y 22; Castromocho, figs. 23, 24 y 25; Covaleda, fig. 26.

383 
Ocenilla.-Este depósito consta de: puñal con empuñadura indeterminada, nervio central y punta "gota de sebo" (fig. 30), y una punta de lanza tubular hasta la base de la hoja (fig. 31). Realizados en bronce.

Layna.-Depósito formado por: dos puntas foliformes (figs. 32 y 33), y una punta de flecha triangular con pedúnculo y aletas (fig. 34).

En función, sobre todo, de las caracteristicas morfológicas que presentan la mayoria de las armas que conforman estos depósitos, ciertamente de tipologia avanzada dentro de la Edad del Bronce, pueden clasificarse cultural y cronológicamente en el Bronce Final (1200) e incluso comienzos del Hierro. Evidentemente la presencia esporádica de armas de tipología antigua en algunos de estos depósitos solo nos confirmarian su pervivencia y uso durante todo o un largo periodo dentro de la Edad del Bronce.

Asi pues, si nos acercamos al panorama que presenta la Meseta peninsular durante este periodo de la Edad del Bronce Final desde el punto de vista del armamento, observamos las manifiestas influencias tipológicas procedentes del exterior, no solo europeas, sino también orientales, consolidándose al mismo tiempo una auténtica metalurgia del bronce sobre todo en aquellas zonas cercanas a los focos de influencia (ver mapa de dispersión, fig. 1).

La mayoria de las armas que han llegado hasta nosotros correspondientes al Bronce Final proceden de hallazgos aislados, sueltos, desconocidos o depósitos, por lo tanto es una constante en todos los casos la ausencia de contexto cultural asi como es imposible, igualmente asociarlas a un tipo de yacimiento concreto.

Estas circunstancias nos resultan curiosas, sobre todo, si las comparamos con los periodos inmediatamente anteriores al Bronce Final, en estos casos observamos como hay armas que pueden asociarse a un tipo de yacimiento concreto caracteristico de un momento cronológico cultural igualmente concreto, claro ejemplo son los puñales de lengüeta y las puntas de flecha palmela presentes en los ajuares funerarios del CalcolíticoBronce Inicial, hasta tal punto que podriamos considerar a los dos ejemplares como armas tipicas funerarias durante dicho momento cultural, evidentemente esto no ocurre con el armamento del Bronce Final, el por qué, ahora mismo, se nos escapa de las manos, si bien, pensamos, que analizando las caracteristicas que presentan los depósitos tratados y el posible significado de los mismos dentro del marco cultural propuesto, puede ofrecernos alguna luz sobre el tema. 
En torno a los depósitos de la Edad del Bronce

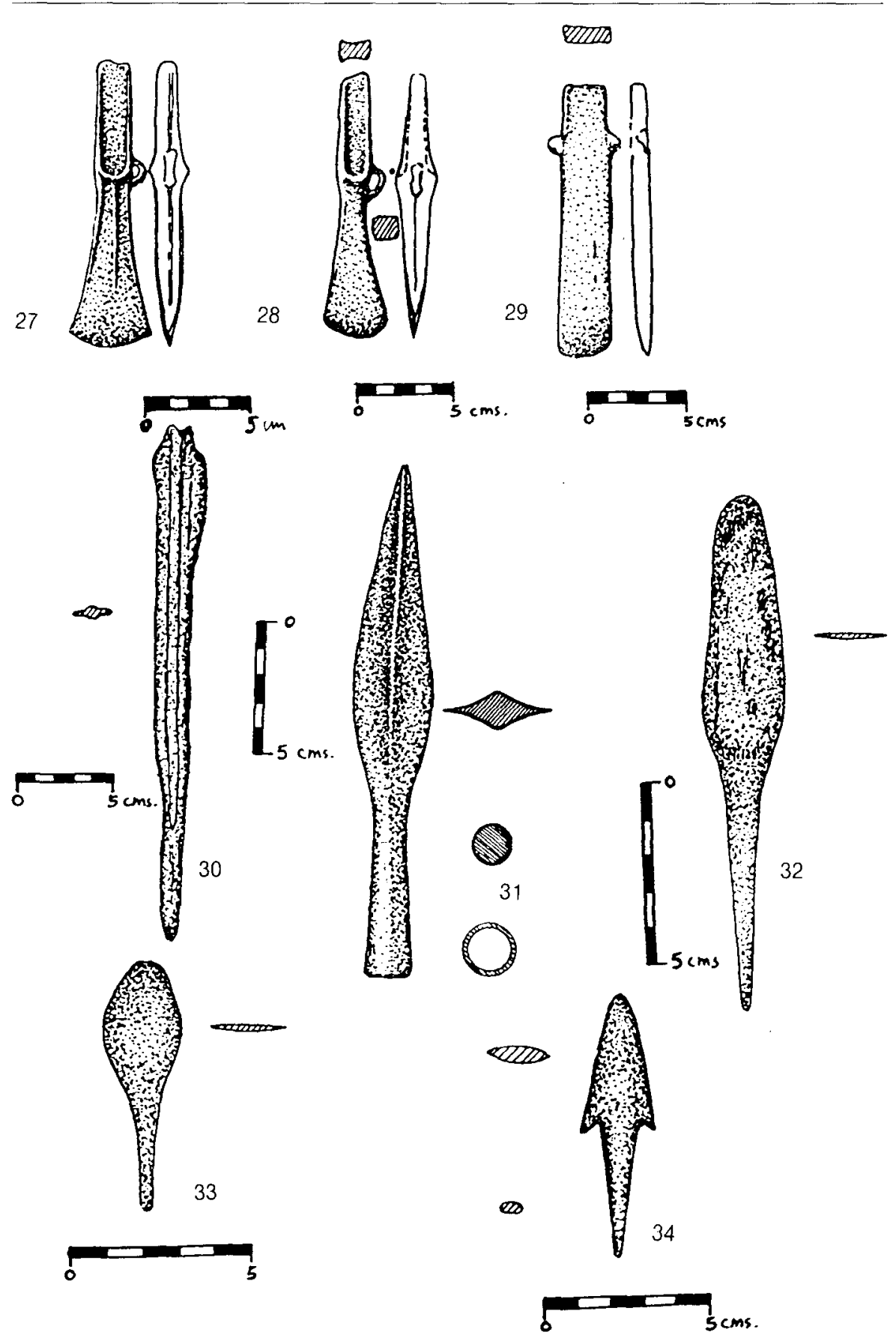

Covaleda, figs. 27, 28 y 29; Ocenilla, figs. 30 y 31; Layna, figs. 32, 33 y 34. 
En este sentido, podemos observar las siguientes caracteristicas en los depósitos:

1. La intencionalidad de depositar juntos un conjunto de útiles, exclusivamente metálicos.

2. Que dentro de estos útiles, son las armas las que tienen el mayor indice de representatividad.

3. Que algunas de estas armas de excelente factura, no han sido utilizadas.

4. ${ }^{\circ}$ El hecho de no poder relacionar estos depósitos a un tipo de yacimiento concreto.

Todas estas circunstancias nos llevan a considerar la posibilidad de que la demanda de estas piezas presentes en los depósitos no procedia de todos los sectores de la sociedad, sino de grupos reducidos de la misma posiblemente de élite y/o jerarquías poderosas, que las solicitaban como bienes de lujo que les permitia mantener su posición de prestigio y poder dentro de esa misma sociedad hasta su muerte. Pero es curioso que en el caso que nos ocupa estos depósitos en ningún caso pueden considerarse como ajuares funerarios, aunque erróneamente así se hayan interpretado alguna vez, ya que no se han encontrado asociados a yacimientos funerarios de ningún tipo, inclinándonos por nuestra parte y en base a lo apuntado en estas lineas a atribuirles un sentido religioso de carácter votivo, es decir, los consideramos como Depósitos votivos, ofrendándose en estos casos, aquellas piezas más preciadas que simbolizaban fuerza, poder y autoridad, dentro de la sociedad vigente, posiblemente pertenecientes a grupos sociales de élite, relacionados con actividades bélicas.

\section{RESUMEN}

El armamento del Bronce Final suele manifestarse en forma de «depósitos cerrados", esta circunstancia, nos permite un análisis tipológico óptimo de ese armamento, pero la disociación de estos depósitos a otros materiales y a un tipo de yacimiento concreto, impide su ubicación exacta en el contexto, tanto de ellos como de los materiales que le conforman.

Este hecho ha motivado que centremos nuestra atención en estos depósitos del Bronce Final, atribuyéndoles, en función de sus propias ca- 
racterísticas y de las que presenta la sociedad en ese momento, un carácter religioso, considerándolos, como Depósitos votivos.

\section{ABSTRACT}

The armament of the Late Bronze Age usually shows up in the form of closed deposits, this circunstance, allow us to make an ideal tipological analysis of that armament, but the disociation of these deposits to other materials and to certain type of site, does not allow us to locate these deposits nor the materials that conform it in their exact context.

All this has induced us to concentrate our attention on these deposits of the Late Bronze Age, ascribing them, depending on their own characteristics and those that represent that moment in the society, a religious characteristic, considering them as votive Deposits.

\section{BIBLIOGRAFIA}

MAC WHITE, E. (1951): “Estudio sobre las relaciones atlánticas de la peninsula hispánica», Disertaciones Matritenses, II. Madrid, págs. 89 y ss, lám. XXII.

Almagro, M. (1943): “Tres nuevos hallazgos del Bronce Final en España", Ampurias, n. "V. Barcelona, págs. 270-280, lám. 1.

- (1967): "Depósito de Represa", Inventaria Archaeologica, n. ${ }^{\circ}$ 7. Madrid

- (1967): "Depósito de Ocenilla”, Inventaria Archaeologica, n." 7. Madrid.

MANANES, T. (1977): "Nuevos hallazgos de la Edad del Bronce en la provincia de León", Cuadernos de Prehistoria y Arqueologia de la Universidad Autónoma de Madrid, n." II. Madrid, págs. 169-176.

Delibes, G. (1975): “Piezas del Bronce Final procedentes de Saldaña en el Museo Arqueológico Provincial de Palencia", Sautuola, n. ${ }^{\circ}$ I. Santander, págs. 149-159.

Delibes, G. y Fernandez Manzano, J. (1983): "Calcolítico y Bronce en tierras de León», Lancia, n. ${ }^{\circ}$ 1. León, pág. 60.

Fernandez Miranda, M. y Balbin, R. (1971): “Piezas de la Edad del Bronce en el Museo Arqueológico provincial de Soria", Trabajos de Prehistoria, n. ${ }^{\circ}$ 28. Madrid, págs. 289-296.

Hernando, A. (1990): "Materiales metálicos de la Edad del Bronce en la meseta: armas", Espacio, Tiempo y Forma, serie I, Prehistoria, t. 3. Madrid, págs. 143-201. 